\title{
TPACK Adaptation among Faculty Members of Education and ICT Departments in University of Sindh, Pakistan
}

\author{
Saira Soomro \\ Department of Distance Continuing and Computer \\ Education, University of Sindh, Elsa Kazi Campus, \\ Sindh, Pakistan
}

Arjumand Bano Soomro

Institute of Information \& Communication Technology

University of Sindh, Jamshoro, Pakistan

Najma Imtiaz Ali

Department of Information Systems,

International Islamic University, Kuala Lumpur, Malaysia/

Institute of Mathematics and Computer Science,

University of Sindh, Jamshoro, Pakistan
Abstract-Technological Pedagogical Content Knowledge (TPACK) framework has been to investigate the technological and instructive knowledge of teachers. Many researchers have found this framework a useful tool to explore teachers' awareness regarding TPACK and how do they are relating it in learning and teaching process in different educational settings. During its first generation time period which was from year 2006 to year 2016, TPACK constructs took a decade to get explained and interpreted by researchers. Now, it has entered in its second generation but still contextual aspect yet not being explored in detail. This study addresses two areas; firstly, to measure the TPACK of faculty members of ICT and Education departments of University of Sindh; and secondly, to unfold the impact of four circumstantial/contextual factors (Technological, Culture of Institute, Interpersonal, and Intrapersonal) on the selected faculty members in using TPACK into their own subject domains. The results showed that both faculties are already taking in technology along with their teaching practices instead of limited technological resources. Besides this, they were found collaborative in teaching and open to the technology. This study reports the TPACK framework adaptation among higher education faculty members at University of Sindh. It also helped in understanding the intrapersonal beliefs of faculty members regarding technology integration with pedagogical and content knowledge.

Keywords-TPACK; teaching-learning; circumstantial and contextual factors

\section{INTRODUCTION}

Effective teaching-learning rely on the subject matter transformation and transfer to the learner in an understandable manner, this refer to the concept of pedagogical content knowledge (PCK). From the beginning of 21 st century,

\author{
Tariq Bhatti \\ Faculty of Education \\ University of Sindh, Elsa Kazi Campus, \\ Hyderabad-76080, Sindh, Pakistan
}

\author{
Nazish Basir \\ Institute of Information \& Communication Technology \\ University of Sindh, Jamshoro, Pakistan
}

\author{
Nazia Parveen Gill \\ Department of Statistics \\ University of Sindh, Jamshoro, \\ Pakistan
}

Information and Communication Technology (ICT) provides new ways to access and process knowledge in every field. In domain of education teachers also started using ICT for transferring their PCK to individual learners in their specific contexts. Higher Education institutions are one of those hubs where this transition is occurring very rapidly. For this the faculty members of higher education institutions should have to meet up with challenges caused by ICT integration into pedagogy and content in their specific subject domains. Technological Pedagogical Content Knowledge (TPACK) framework defines how ICT can be blended with pedagogical and content knowledge. The purpose of this research was to observe the TPACK awareness and adaptation among the faculty members at higher education institutions. The researchers have tried to explore and compare the TPACK knowledge of IT and Education Faculty of University of Sindh, Jamshoro Pakistan. The findings of this study will become a fact-finding analysis for teachers to improve their TPACK knowledge in respective subject domain.

\section{LITERATURE REVIEW}

An effective teaching encompasses the continuous improvement in teaching methods, in subject content and effective use of ICT (Information and Communication Technology) in teaching [1]. The TPACK framework gives a baseline to teachers about the integration of knowledge, content, pedagogy and ICT.

The first model of PCK (Pedagogical content knowledge) was suggested by Shulman [2] as shown in Fig. 1, it was further derived, rearranged and represented as TPACK by Mishra and Koehler [3]. TPACK is an extension of pedagogical content knowledge (PCK) concept. It has seven 
complex constructs known as: 1) knowledge of technology (TK), 2) knowledge of content (CK), 3) knowledge of pedagogy (PK), 4) knowledge of pedagogy content (PCK), 5) knowledge of technology content (TCK), 6) knowledge of technology pedagogy (TPK), and 7) technological pedagogical content knowledge (TPACK) [4]-[8].

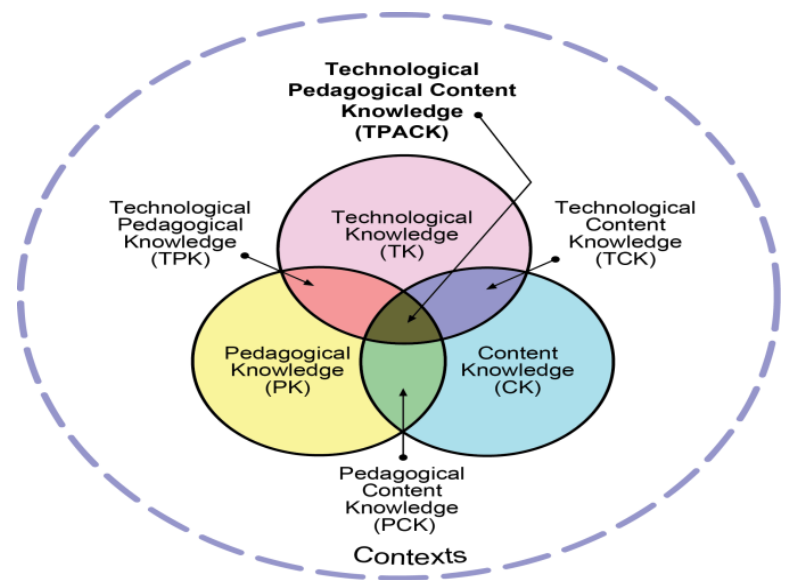

Fig. 1. Schema of Technological Pedagogical Content Knowledge (TPACK) source: [26]

The technological knowledge (TK), refers to the use of management and maintenance of ICT technologies such as wireless broadband, dial-up internet connection, digital photos and videos creation, software programs and hardware, and the use of interactive whiteboards, blackboards [3], [8]-[10] .

Content knowledge (CK) is the knowledge of subject content which students expect to learn from teachers. The subject teacher is required to get equipped with sufficient content knowledge so he/she would be able to provide explanations to the students' queries [9], [11]. For the effective delivery of subject content, the pedagogy knowledge is required for teachers. It comprises of the knowledge of classroom instructions, classroom management skills, strategies for effective teaching, session planning and different assessment methods in alignment of set learning objectives of that particular session [9], [12]. The pedagogical content knowledge (PCK) refers to the particular knowledge of pedagogy that is suitable for specific subject content [6]. For better results of teaching instructions, the combination of pedagogy and content knowledge is essential [3], [9]. Technological content knowledge (TCK) helps in understanding that how different technologies can be used with subject contents to make teaching-learning process more effective [3]. Technological pedagogical knowledge (TPK) is an effective application of technology into teaching practices by the teachers. It can improve the instructions given to the students and help them in learning more effective way [4], [10], [13]. Finally the technological pedagogical content knowledge (TPACK) is fitting together the knowledge of content, technology, and pedagogy for delivery of subject content in efficient and effective manner [3].

Several studies have been conducted to authenticate the TPACK framework in different subject domains but most of them were conducted only on teacher educators or on preservice teachers [5], [6], [14]-[19].
A 30-item questionnaire was developed by Lee and Tsai [16] to measure the World Wide Web (WWW) knowledge among teachers. The instrument used TPACK model as a framework. In total 558 teachers were selected from different Taiwan's schools were selected. The TPACK framework has been used to measure their Web knowledge at two levels, the Web knowledge in general and Web knowledge in communication.

Another study done by Koh, Chai and Tsai [20] to observe the TPACK knowledge of 1185 pre-service teachers who were enrolled in the Postgraduate Diploma/Diploma in Education programme at a higher education institute in Singapore. They performed exploratory factor analysis and found five out of seven TPACK constructs distinctive, namely technological knowledge, content knowledge, knowledge of pedagogy, knowledge of teaching with technology and knowledge from critical reflection. They reported that the participants of the study were unaware of differences between the TPACK constructs, particularly technological content knowledge and technological pedagogical knowledge.

Doukakis et al. [21] have adopted the TPACK framework and its instrument to measure the TPACK knowledge among upper secondary in-service teachers in Greece. The results showed that the sample of 1032 computer science teachers were high in content and technology knowledge. The teachers were found below average in their pedagogical content knowledge and technological content knowledge. This shows that they were unaware or unable to apply suitable teaching technique and technology both together in their subject area for teaching. In conclusion they still need to be guided to improve their PCK and TCK.

In another study conducted by Liang et al. [22], the inservice pre-school teachers were assessed by using an instrument based on TPACK in Taiwan. Their study explored 336 educational technology teachers by using the 42 -items TPACK survey originally including seven scales (CK, PK, PCK, TK, TPK, TCK and TPCK) as discussed earlier in this paper. They performed exploratory factor analysis (EFA) to test reliability and validity of instrument which was adequate. The EFA also produced six scales, out of which five were same as per the original TPACK framework (i.e. CK, PK, PCK, TK and TPCK) and the sixth one was combination of technological pedagogical knowledge and technological content knowledge (TPTCK). Further results showed that pre-school teacher with more seniority possessed a certain level of resistance against technology-based teaching. It was also reported that teachers higher education qualification were more equipped with technological knowledge and comfortable with technology integrated teaching environment.

In a recent study of Mahmud [23] the TPACK has been used to assess English subject teachers in Indonesian context. The researcher through random sampling selected 74 in-service senior high school teachers. The 45 -items based instrument validation and reliability reported as good. The results showed the English subject teachers at senior high school Pekanbaru, Indonesia were capable in integrating technology with content and pedagogy, as most of the teachers were experienced with good qualification. The factors with technology e.g. TCK, TK, 
TPK and TPCK reported were reported low in their mean score. The researcher related this low score with the teachers' age and the English subject which they teach as it has no direct association with the technology. To bring the technological competency in teachers the author recommended the authorities and technical experts to facilitate teachers in acquire technological knowledge.

The TPACK model is a knowledge triad of content, pedagogy and technology and this intersected framework is compulsory for teachers to acquire for effective teachinglearning process. Before this TPACK framework was only used to measure the triad knowledge of teacher educators. In this paper this triad knowledge of other higher education teachers was measured and different insights will have explored due to different subject domains.

\section{METHODOLOGY}

\section{A. Research Method}

Within the framework of mixed method approach, the present study was based on survey procedures [24]. By using this procedure, both quantitative and qualitative data have been collected and analyzed. In beginning the quantitative study has been conducted by using a survey questionnaire. Then followed by a qualitative method in which researchers planned interviews for qualitative data collection. Mixed method allows the researcher to gain more insight from the combination of both qualitative and quantitative research [24]. This particular design is selected for two main reasons. Firstly, it offers an opportunity to counterbalance the weaknesses embedded within one method with the strengths of the other. Secondly, it helps researchers to perform exploration with a few cases or individuals (see Fig. 2).

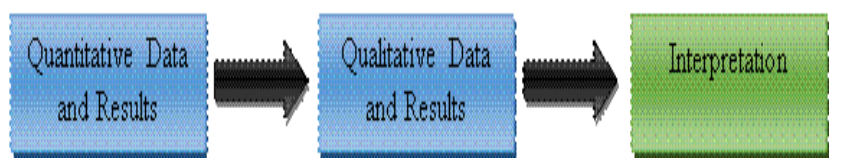

Fig. 2. Conceptual framework of survey procedure.

\section{B. Population}

The target population for the study included all faculty members of departments of ICT and Education at University of Sindh, Pakistan. This population would have consisted of 38 faculty members of department of ICT and 26 faculty members of Department of Education.

\section{Sample}

Multistage sampling procedure was used because of study mixed method design. At the first stage, all faculty members were employed were selected as a sample of the study for the collection of quantitative data which include (26) Department of Education and (38) ICT faculty members. At the second stage for making sample highly representative two participants were selected from each department were selected for interviews.

\section{Response Rate}

The overall response rate was (67\%), 43 questionnaires have been returned out of 64, which were distributed among faculty members of ICT (38) and Department of Education
(26). From Department of Education (21) were returned $(80.7 \%)$ and from ICT (22) were returned $(57.89 \%)$.

\section{E. Research Instruments}

In this study, the questionnaire, and interview were selected as instruments for collecting data from the participants. In this study, the instruments to collect data from the participants were questionnaire, in-depth interview and focus group discussion.

\section{F. Questionnaire}

For the first research question the questionnaire was used. The questionnaire consisted on seven constructs of TPACK and adopted from the study "DEVELOPMENT OF SURVEY OF TECHNOLOGICAL PEDAGOGICAL AND CONTENT KNOWLEDGE (TPACK)" already conducted by I. Sahin [15]. As the instrument's reliability and validity was already tested, so pilot testing was not directed.

Interviews: The interview was consisted of eight questions. From the all interviews four themes were emerged to address the second research question. All interviews were audio recorded. The qualitative data produced through interviews were analyzed for major themes to address the research questions that were posted at the outset of this study.

\section{RESULTS}

We tried to answer our first research question in this part of the paper. The research question is given below.

Q\#1. What difference can be found in measuring TPACK knowledge among university faculty of different subject domains (I.T and Education)?

\section{A. Questionnaire Results}

Subjects: In total the subject of this research were 43 University of Sindh teachers, out of which 21 affiliated with Department of Education and 22 with department of ICT. The respondents belong to different job levels and working experience (see Tables I and II). Most of the participants (32) were female $(74.4 \%)$ out of total 43 and (11) were male (25.5\%). In faculty, wise gender distribution there were (14) females (66.6\%) and (7) male (33.3\%) in Department of Education. In ICT, the female participants were (12) that was $(55 \%)$ and (10) were male (45.45\%).Define abbreviations and acronyms the first time they are used in the text, even after they have been defined in the abstract. Abbreviations such as IEEE, SI, MKS, CGS, sc, dc, and rms do not have to be defined. Do not use abbreviations in the title or heads unless they are unavoidable.

TABLE I. WORK EXPERIENCE VICE DISTRIBUTION

\begin{tabular}{|l|l|}
\hline Work Experience (in years) & No. of Participants \\
\hline $1-5$ & 17 \\
\hline $6-10$ & 4 \\
\hline $11-15$ & 10 \\
\hline $16-20$ & 7 \\
\hline $21 \&$ above & 5 \\
\hline
\end{tabular}


TABLE II. JOB VICE DISTRIBUTION

\begin{tabular}{|c|c|}
\hline Job Title & No. of Participants \\
\hline Research Associate & 8 \\
\hline Instructor/Lecturer & 18 \\
\hline Assistant Professor & 16 \\
\hline Associate Professor & 1 \\
\hline
\end{tabular}

\section{B. TPACK score distribution}

In Fig. 3 the distribution shows the Technological Knowledge (TK) has considerably has higher score among all. It also shows that department of education is lower in Technological Pedagogical Knowledge (TPK).

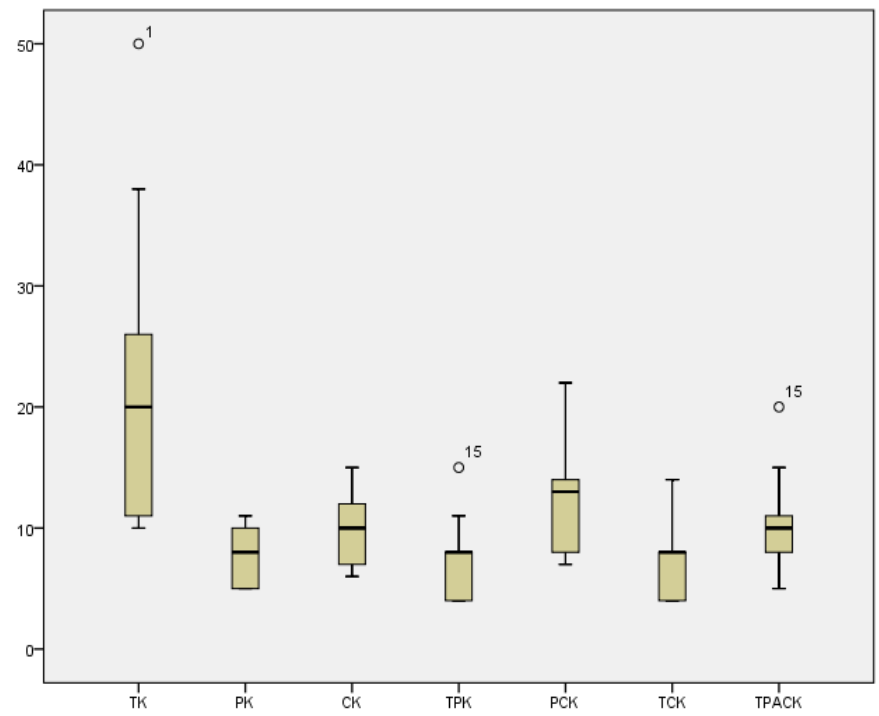

Fig. 3. TPACK adaptation in Department of Education.

In Fig. 4, the Pedagogical Content Knowledge (PCK) scores distribution much higher than other TPACK factors. And Technological Content Knowledge (TCK) has lowest score distribution among all within faculty members of ICT.

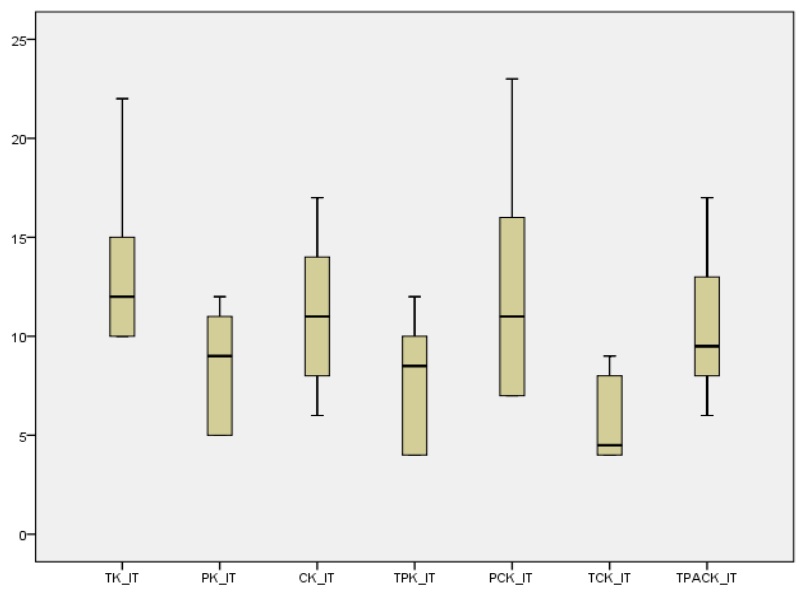

Fig. 4. TPACK adaptation in ICT.

In Fig. 5, the overall TPACK score distribution for ICT and Education department can be seen together.

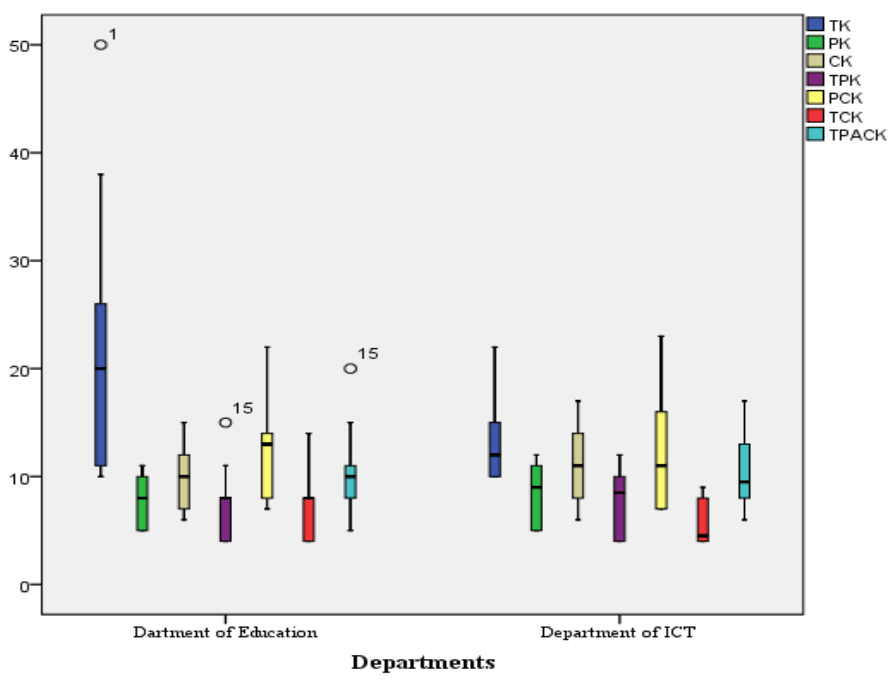

Fig. 5. Overall factor vice score distribution.

Fig. 6 shows the overall score distribution for TPACK adapted by both faculty members of ICT and Education. The figures show there is overlapping in boxes, therefore there is likely to be a difference between both groups. Although the score distribution for ICT faculty members seem higher but the median values for both (10) department of education and (9) ICT are nearly same.

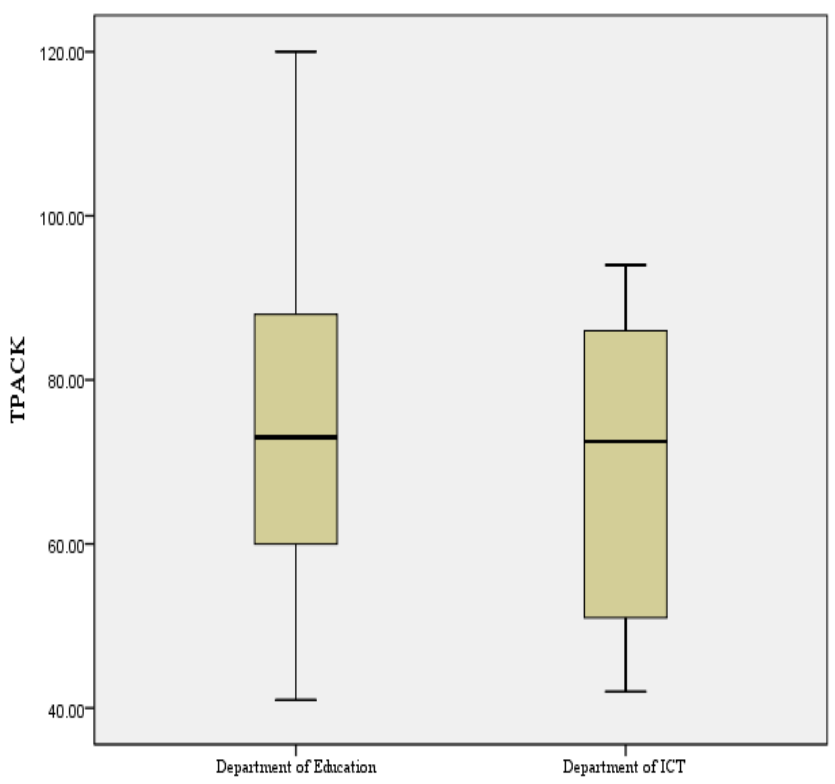

Fig. 6. TPACK adaptation in departments of Education and ICT.

In Fig. 7, the histogram for department of Education can be seen, it contains outlier data. In the graphical check for outliers in data we have already generated the box plots (see Fig. 2 and 4). The reason for these outliers could be the unusual or unrealistic response towards the TPACK adaptation, particularly factors TK, TPK and TPACK. 


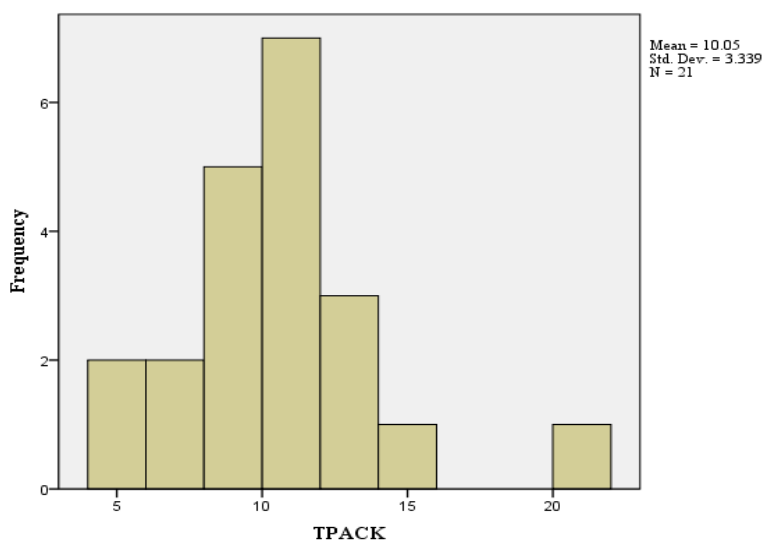

Fig. 7. Histogram for Department of Education.

In the similar way the Fig. 8 also showing outliers in the histogram diagram for department of ICT. But for this the box plot (see Fig. $2 \& 4$ ) there are no outliers shown.

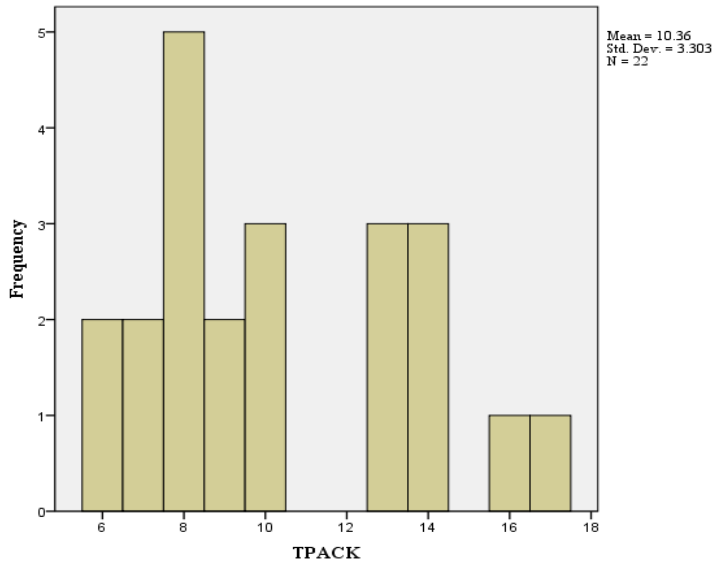

Fig. 8. Histogram for department of ICT.

For further check the Q-Q plots also generated (see Fig. 9 and 10). In Fig. 8, an outlier can be noticed prominently on the other hand Fig. 8 has no outliers in it. Beside this both Q-Q plots show the normality of data upto some level. Although in case of ICT (see Fig. 10) the points are bit far from normal line and it also show there are two groups within data among which, one is outlying from the other part.

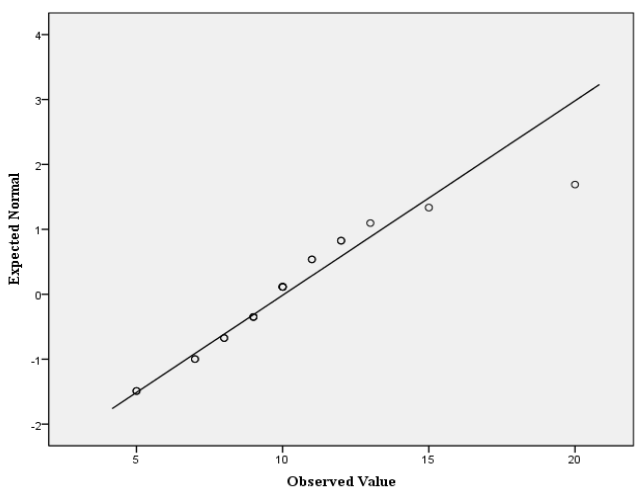

Fig. 9. Q-Q plot for Department of Education.

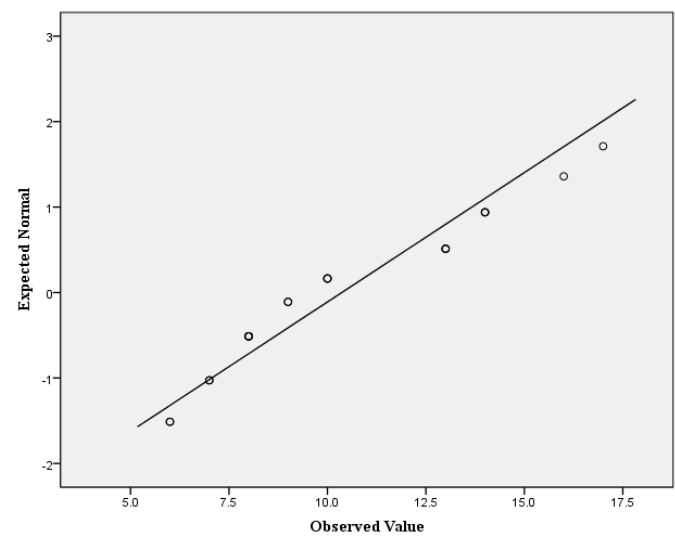

Fig. 10. Q-Q plot for Department of ICT.

\section{Interview Results}

Q\#2. How the circumstantial/contextual factors affect the TPACK of individual faculty?

This question brought four themes to the forefront of the study, (a) Technological (b) Culture of institute (c) Intrapersonal and (d) Interpersonal. Under each theme different questions were from participants of each research site.

\section{1) THEME 01: TECHNOLOGICAL}

Q1 Is computer available at your office for session planning?

Participant\#1 "Yes, computers are available in every office."

Partcipant\#2 "Each faculty member has his/her personal laptops."

Participant\#3 "Yes, computers are available for use."

Participant\#4 "Almost every faculty member has their own laptop bought personally by them".

Q2 Does your department provide you fully furnished computer lab with updated hardware and software in executing your sessions?

Participant\#1 "No, computer lab is not updated for classes because funds are properly given."

Partcipant\#2 "Yes, as I belong to ICT department so there are 5 to 6 computer labs."

Participant\#3 "Yes, fully furnished computer labs are available for use."

Participant\#4 "We do not take classes in lab, each faculty bring their laptop to conduct practical if they wish to use computer in class."

\section{2) THEME 02: CULTURE OF INSTITUTE}

Q3 Is your nationwide higher education policies promote technology use with pedagogy and content?

Participant\#1 "Yes, there are various but technology with pedagogy is a bit difficult." 
Partcipant\#2 "Yes, we use technology with content but as we are from ICT department so most of the faculty members do not have B.Ed. / M.Ed degrees."

Participant\#3 "Yes, few of the teachers of education department use technology with content and pedagogy."

Participant\#4 "Using technology with pedagogy is our strength, but computer lab setup restricts us for extensive use."

Q4 Do you integrate technology into course outlines of various subjects of your domain?

Participant\#1 "Yes, as technology is our subject so we use it frequently."

Partcipant\#2 "Yes, we technology with content subjects."

Participant\#3 "Yes, few of the teachers to integrate technology with their subjects."

Participant\#4 "We have devices like multimedia projector and other technology tools."

3) THEME 03: INTRAPERSONAL

Q5 What are your beliefs about using technology into teaching-learning process?

Participant\#1 "Technology boosts teaching-learning, and can help teachers to achieve their session objectives."

Partcipant\#2 "Technology helps us as a teacher to make our students clear about the topics of the course."

Participant\#3 "Yes, I believe that technology helps teachers to integrate technology with their subjects."

Participant\#4 "We use different devices like multimedia projector and other technology tools."

4) THEME 04: INTERPERSONAL

Q6 Do you think collaboration with colleagues increases your motivation to use technology into teaching-learning process?

Participant\#1 "Yes, with help and collaboration of colleagues increases our motivation"

Partcipant\#2 "It depends on department environment to use technology with collaboration into teaching-learning process."

Participant\#3 "Yes, I believe that technology helps teachers to do team teaching."

Participant\#4 "We use different collaboration tools in collaboration with other teachers."

The second research question "How the circumstantial/ contextual factors affect the TPACK of individual faculty?" uncovered the effect of circumstantial/ contextual factors on teachers' TPACK. The factor that influenced teachers' TPACK was the Technological devices availability. The result of interview showed positive trend towards technology availability. Most of the faculty members have personal laptops. On the fully furnished computer labs the researcher got mixed responses. As in ICT department there were 5 to 6 labs but in comparison to education department they possess only one lab. The second factor was culture of institute in which researcher got responses on nationwide policies for technology. One participant answered that "Yes, there are various policies but using technology with pedagogy is bit difficult". Another said that "We believe in technology with content but as we are from ICT department so most of the faculty does not have B.Ed./M.Ed". On enquiry of one question about technology integration researcher received the answers that "We use technology is our subject frequently". Another participant said that, "Yes few of the teachers integrate technology in their subjects". From the result, it is obvious teachers need more time and effort to use technology into subjects as a pedagogy but still students' skills regarding ICT skills need to be studied. The interview further explored the teacher's intrapersonal beliefs in which they said that technology helps us as a teacher to make our students clear about the topics of the course. Another said they believe that technology helps teachers to teach subjects with more clarity. This same belief was also found in a study beliefs influence their practice of ICT integration [25].

\section{DISCUSSION}

Pakistan is a developing country although the technology trends are not unfamiliar in this region but still the adaptation is slow. Especially in the field of education there is still no proper infrastructure which can pursue teacher and learner to adapt technology in their teaching-learning process.

University of Sindh situated in the Province of Sindh at the distance of around $155 \mathrm{~km}$ from the capital city Karachi. Although this University is not rich in ICT resources but faculty members are well equipped with the knowledge of using the technological instruments and try to implement in their teaching-learning process.

Being the part of this University faculty we conducted this study to get the clear picture about other faculty members' perceptions and approach to adapt TPACK in their particular domain of teaching. For this we chose two departments ICT and education, one of the reasons to choose these was the easy access to the faculty members and to get their response on time as two of the authors belong to these departments, this helped us in data collection through questionnaires and interviews.

The results produced from the data collected through questionnaires were unable to provide us the clear picture therefore we have conducted interviews. While comparing the two groups of data or in other words to do analysis of variance we needed to do some checks. The main requirement for this parametric technique to compare the groups was the continuous scale instead of discrete, the TPACK instrument contained 5-point Likert scale, the other check was the random sampling, the number of faculty members of our selected departments was small therefore we employed all the faculty members which made us to violate this second check. The third check was to keep the observations independent, during questionnaire distribution we visited the individual faculty members in their offices instead of a particular venue where they gather and do discussions. For the normality check we ran explore in SPSS 22 the results are given in the data analysis part. The outliers in results and the violation of second that was random sampling made us to conduct the interviews. Besides all these issues the questionnaire part was not totally worthless 
it helped us to answer our first research question and up to some level we figured out about the TPACK factors which were highly adapted in both faculty members of ICT and Education department.

From interviews, it revealed that both faculties are already persuaded to incorporate technology in their teaching and learning process, although the technological resources are not sufficient but they are compensating this by having their personal gadgets. They have no issue in collaborative teaching and they are also open to the technology. Only if there would be a technological infrastructure, then they can employ TPACK in more effective manner.

\section{ACKNOWLEDGMENT}

We acknowledge faculty members of I.T. and Education Faculty University of Sindh, Jamshoro, who voluntarily participated in this study and gave their precious time to this insight sharing activity, which became a research study ultimately.

\section{REFERENCES}

[1] G. Alayyar, P. Fisser, and J. Voogt, "Developing technological pedagogical content knowledge in pre-service science teachers: Support from blended learning,” Australas. J. Educ., 2012.

[2] L. Shulman, "Those who understand: Knowledge growth in teaching," Educ. Res., 1986.

[3] P. Mishra and M. Koehler, "Technological pedagogical content knowledge: A framework for teacher knowledge," Teach. Coll. Rec., 2006.

[4] E. Baran, H. H.-H. Chuang, and A. Thompson, "tpack: an emerging research and development tool for teacher educators," Turkish online J. Educ. Technol., vol. 10, no. 4, pp. 370-377, 2011.

[5] D. Schmidt, E. Baran, and A. Thompson, "Technological pedagogical content knowledge (TPACK) the development and validation of an assessment instrument for preservice teachers," J. Res., 2009.

[6] M. Koehler and P. Mishra, "What happens when teachers design educational technology? The development of technological pedagogical content knowledge," J. Educ. Comput. Res., 2005.

[7] M. Koehler, P. Mishra, and K. Yahya, "Tracing the development of teacher knowledge in a design seminar: Integrating content, pedagogy and technology," Comput. Educ., 2007.

[8] M. Koehler and P. Mishra, "What is technological pedagogical content knowledge," issues Technol. Teach. Educ., 2009.

[9] "TPACK: An emerging research and development tool for teacher educators," TOJET: The Turkish, 2011.
[10] M. Koehler and P. Mishra, "Introducing TPCK. AACTE Committee on Innovation and Technology (Ed.), The handbook of technological pedgogicalcontent knowledge (TPCK) for," 2008.

[11] P. Nilsson, “Teaching for understanding: The complex nature of pedagogical content knowledge in pre - service education," Int. J. Sci. Educ., 2008.

[12] J. Hinostroza, C. Labbé, L. López, and H. Iost, "Traditional and emerging IT applications for learning," Int. Handb., 2008.

[13] J. Harris, P. Mishra, and M. Koehler, "Teachers' technological pedagogical content knowledge and learning activity types: Curriculumbased technology integration reframed," J. Res. Technol., 2009.

[14] S. Jang and M. Tsai, "Exploring the TPACK of Taiwanese elementary mathematics and science teachers with respect to use of interactive whiteboards," Comput. Educ., 2012.

[15] I. Sahin, "Development of survey of technological pedagogical and content knowledge (TPACK)," TOJET Turkish Online J. Educ., 2011.

[16] [M. Lee and C. Tsai, "Exploring teachers' perceived self efficacy and technological pedagogical content knowledge with respect to educational use f the World Wide Web," Instr. Sci., 2010.

[17] C. Angeli and N. Valanides, "Epistemological and methodological issues for the conceptualization, development, and assessment of ICTTPCK: Advances in technological pedagogical content," Comput. Educ., 2009.

[18] [18] L. Archambault and K. Crippen, "Examining TPACK among K-12 online distance educators in the United States," Contemp. issues Technol., 2009.

[19] R. Graham, N. Burgoyne, P. Cantrell, L. Smith, and L. S. Clair, "Measuring the TPACK confidence of inservice science teachers," TechTrends, 2009.

[20] J. Koh, C. Chai, and C. Tsai, “Examining the technological pedagogical content knowledge of Singapore pre - service teachers with a large - scale survey," J. Comput. Assist., 2010.

[21] S. Doukakis, A. Psaltidou, and A. Stavraki, "Measuring the technological pedagogical content knowledge (TPACK) of in-service teachers of computer science who teach algorithms and programming in,” Technol. ..., 2010.

[22] J. Liang, C. Chai, J. Koh, C. Yang, and C. Tsai, "Surveying in-service preschool teachers' technological pedagogical content knowledge," 2013.

[23] M. Mahdum, "Technological Pedagogical and Content Knowledge (TPACK) of English Teachers in Pekanbaru, Riau, Indonesia," Mediterr. J. Soc. Sci., 2015.

[24] J. W. Creswell, Research Design: Qualitative, Quantitative and Mixed Method Aproaches. Sage Publications Inc., 2013.

[25] P. Ertmer, A. Ottenbreit-Leftwich, and O. Sadik, "Teacher beliefs and technology integration practices: A critical relationship," Comput., 2012.

[26] http://www.tpack.org/tpck/index.php?title=TPCK_ _Technological_Pedagogical_Content_Knowledge 